\title{
Effects of remote ischemic preconditioning in high-risk patients undergoing cardiac surgery (Remote IMPACT): a randomized controlled trial
}

\author{
Michael Walsh MD PhD, Richard Whitlock MD PhD, Amit X. Garg MD PhD, Jean-François Légaré MD PhD, \\ Andra E. Duncan MD, Robert Zimmerman MD, Scott Miller MD, Stephen Fremes MD, Teresa Kieser MD, \\ Ganesan Karthikeyan MD MSc, Matthew Chan MB BS, Anthony Ho MD, Vivian Nasr MD, Jessica Vincent MSc, \\ Imtiaz Ali MD PhD, Ronit Lavi MD, Daniel I. Sessler MD, Robert Kramer MD, Jeff Gardner MD, Summer Syed MD, \\ Tomas VanHelder MD PhD, Gordon Guyatt MD MSc, Purnima Rao-Melacini MSc, Lehana Thabane PhD, \\ P.J. Devereaux MD PhD; for the Remote IMPACT Investigators
}

\begin{abstract}
Background: Remote ischemic preconditioning is a simple therapy that may reduce cardiac and kidney injury. We undertook a randomized controlled trial to evaluate the effect of this therapy on markers of heart and kidney injury after cardiac surgery.
\end{abstract}

Methods: Patients at high risk of death within 30 days after cardiac surgery were randomly assigned to undergo remote ischemic preconditioning or a sham procedure after induction of anesthesia. The preconditioning therapy was three 5-minute cycles of thigh ischemia, with 5 minutes of reperfusion between cycles. The sham procedure was identical except that ischemia was not induced. The primary outcome was peak creatine kinasemyocardial band (CK-MB) within 24 hours after surgery (expressed as multiples of the upper limit of normal, with log transformation). The secondary outcome was change in creatinine level within 4 days after surgery (expressed as log-transformed micromoles per litre). Patient-important outcomes were assessed up to 6 months after randomization.

Results: We randomly assigned 128 patients to remote ischemic preconditioning and 130 to the sham therapy. There were no significant differences in postoperative CK-MB (absolute mean difference $0.15,95 \%$ confidence interval [Cl] -0.07 to 0.36 ) or creatinine (absolute mean difference $0.06,95 \% \mathrm{Cl}-0.10$ to 0.23 ). Other outcomes did not differ significantly for remote ischemic preconditioning relative to the sham therapy: for myocardial infarction, relative risk (RR) 1.35 (95\% Cl 0.85 to 2.17); for acute kidney injury, RR 1.10 (95\% Cl 0.68 to 1.78$)$; for stroke, RR 1.02 (95\% Cl 0.34 to 3.07); and for death, RR 1.47 (95\% Cl 0.65 to 3.31$)$.

Interpretation: Remote ischemic preconditioning did not reduce myocardial or kidney injury during cardiac surgery. This type of therapy is unlikely to substantially improve patientimportant outcomes in cardiac surgery. Trial registration: ClinicalTrials.gov, no. NCT01071265.
Competing interests: Richard Whitlock has received consultancy fees from Armetheon. P.J. Devereaux has received grants from Abbott Diagnostics, Boehringer Ingelheim, Covidien, Octopharma, Roche Diagnostics and Stryker.

No other competing interests were declared.

This article has been peer reviewed.

Accepted: Oct. 26, 2015 Online: Dec. 14, 2015

Correspondence to: Michael Walsh, lastwalsh1975@gmail.com

CMAJ 2016. DOI:10.1503/ cmaj.150632
$\mathrm{E}$ ach year, 2 million patients worldwide undergo cardiac surgery. For more than $25 \%$ of these patients, the surgery is complicated by myocardial infarction (MI) and/or acute kidney injury, both of which are strongly associated with morbidity and mortality. ${ }^{1-3}$ Preventing MI and acute kidney injury after cardiac surgery would improve survival.

An important cause of MI and acute kidney injury in patients undergoing cardiac surgery is ischemia-reperfusion injury. ${ }^{4,5}$ This type of injury begins as ischemia, which is then exacerbated by a systemic inflammatory response upon restoration of organ perfusion. ${ }^{6}$ Remote ischemic preconditioning may mitigate ischemia- reperfusion damage. It is accomplished by inducing, before surgery, brief episodes of ischemia in a limb, which lead to widespread activation of endogenous cellular systems that may protect organs from subsequent severe ischemia and reperfusion..$^{7-9}$

Small randomized controlled trials evaluating the efficacy of remote ischemic preconditioning have had mixed results. ${ }^{10-17}$ Interpretation of their data is difficult because of small sample sizes and heterogeneity in the preconditioning procedures and patient populations (e.g., few trials have evaluated patients at high risk of organ injury and postoperative death). Whether remote ischemic preconditioning effectively 
mitigates ischemia-reperfusion injury therefore remains uncertain. We undertook the Remote Ischemic Preconditioning in Cardiac Surgery Trial (Remote IMPACT) to determine whether this procedure reduces myocardial and kidney injury. We proposed that a large trial to determine the effect on clinically important outcomes would be worthwhile only if a substantial effect on myocardial or kidney injury, or both, were observed in the current study.

\section{Methods}

\section{Setting}

We conducted a blinded, parallel-group randomized controlled trial comparing remote ischemic preconditioning with a sham procedure in patients undergoing cardiac surgery at 11 centres in 4 countries (Canada, United States, India and China). Before patient recruitment began, the research ethics board at each participating institution reviewed and accepted the protocol (which was first approved by the Hamilton Health Sciences Research Ethics Board), and all participants provided written informed consent.

\section{Patients}

Recruitment took place between March 2011 and March 2012. Patients were eligible if they were undergoing cardiac surgery (whether onpump or off-pump), were 18 years of age or older, and were at high risk of postoperative death, as indicated by an additive score of at least 6 with the European System for Cardiac Operative Risk Evaluation (EuroSCORE).$^{18}$ Previous research showed that, among patients undergoing valvular surgery, the risk of death for patients in India and China with EuroSCORE values of at least 4 was similar to that for North American patients with EuroSCORE values of at least $6 .{ }^{19,20}$ Therefore, in the current study, eligibility was extended to patients undergoing valvular surgery in Indian and Chinese centres who had a EuroSCORE value of 4 or above. Patients were excluded if an intra-aortic balloon pump was used before surgery.

\section{Randomization and blinding}

After obtaining written informed consent, research personnel used a computerized Internetbased randomization system maintained by the coordinating centre (the Population Health Research Institution, Hamilton, Ontario) to randomly assign patients to treatment groups. An independent statistician generated block randomization, with randomly varying block sizes, stratified by centre and by whether the patient received long-term dialysis. Study centre personnel were not aware of the block sizes. Randomization occurred as close as possible to the time of surgery, to reduce the risk of including patients who ultimately did not undergo surgery. Participants, health care providers (surgeons, anesthetists and operating room staff) and outcome adjudicators were blinded to treatment allocation.

\section{Procedures}

All centres used centrally supplied sterile, disposable, manually inflated thigh tourniquets (VBM Medical Inc.). After induction of anesthesia and before commencement of bypass (while the graft was being harvested), research staff applied a pneumatic tourniquet to one thigh of the participant (on the opposite side to harvesting) and draped the tourniquet system to prevent operating room staff from seeing whether or not the cuff was inflated. Patients assigned to undergo remote ischemic preconditioning had 3 cycles of tourniquet inflation to $300 \mathrm{~mm} \mathrm{Hg}$, to generate 5 minutes of ischemia, between which the cuff was deflated for 5 minutes of reperfusion. Patients assigned to undergo the sham procedure had 3 cycles of tourniquet inflation to $15 \mathrm{~mm} \mathrm{Hg}$ for 5 minutes, separated by deflation for 5 minutes. Because the study procedure was done during graft harvesting, there was no meaningful effect on surgical workflow. This protocol for remote ischemic preconditioning was chosen because provision of 3 cycles of ischemia has been well studied and appeared effective in previous trials and because leg ischemia has the potential to induce ischemia in a larger mass than arm ischemia and thus may provide a larger preconditioning stimulus.

Samples for determination of creatine kinasemyocardial band (CK-MB) level were drawn 8 and 24 hours after the procedure; the assays were performed at each study centre's local laboratory. Serum creatinine was measured within 1 day before surgery and then each morning daily for 4 days, starting the day after surgery. Patients were followed for postoperative events during their hospital stay and up to 6 months after surgery.

\section{Outcomes}

The primary outcome was peak level of CK-MB within the first 24 hours after surgery, expressed as multiples of the upper limit of normal, because this variable is strongly related to postoperative death. ${ }^{21}$ The main secondary outcome was the absolute difference between preoperative creatinine level and highest creatinine level during the first 4 days after surgery. We chose change in serum creatinine (a continuous variable) because it has better statistical power than categories of acute kidney injury. Other second- 
ary outcomes were MI, acute kidney injury, stroke and all-cause mortality up to 6 months after randomization. Within the first 72 hours after surgery, MI was defined as CK-MB at least 8 times the upper limit of normal ( $\geq 5$ times for patients with isolated coronary artery bypass graft $[\mathrm{CABG}]$ ), angiographic evidence of vessel occlusion or imaging evidence of new loss of myocardium. Starting 72 hours after surgery, diagnosis of MI required elevation of a cardiac enzyme above the upper reference limit and ischemic electrocardiography changes. In accordance with the Acute Kidney Injury Network classification, we defined acute kidney injury as an increase in serum creatinine of at least 1.5 times or $26.4 \mu \mathrm{mol} / \mathrm{L}(0.3 \mathrm{mg} / \mathrm{dL})$, relative to the preoperative value, or initiation of dialysis. ${ }^{22}$ Patients who needed dialysis before surgery were excluded from analyses of change in creatinine or acute kidney injury. Stroke was defined as a new focal neurologic deficit thought to be vascular in origin, with signs or symptoms lasting more than 24 hours or resulting in death.

\section{Statistical analysis}

We estimated the sample size required on the basis of both peak CK-MB and change in serum creatinine. The sample size for the study was ultimately based on the creatinine outcome, because it required a marginally larger sample size under our assumptions. We assumed a mean change in serum creatinine of $36 \mu \mathrm{mol} / \mathrm{L}$. Using log-transformed values to normalize these data, we expected a mean change of 2.5 (standard deviation 1.5), with coefficient of variation of 0.9 . We considered that a reduction in peak serum creatinine of $25 \%$ or greater would be required to improve clinically important outcomes. We therefore needed 114 participants in each arm (228 total) to detect a reduction of at least $25 \%$ with $80 \%$ power and a 2 -sided $\alpha$ of 0.05 , using analysis of covariance. For CK-MB, the sample size of 228 participants estimated at least $95 \%$ power to detect a between-group difference of $0.4 \log$-transformed multiples of the upper limit of normal (equivalent to a betweengroup difference of about $10 \mathrm{U} / \mathrm{L}$ for mass-based assays), assuming a standard deviation of 0.8 log-transformed units. Calculations were performed with PASS software, version 8.08 (NCSS, LLC). We inflated the recruitment goal to 250 patients to account for potential missing data and the fact that patients with end-stage renal disease at enrolment would not be eligible for assessment of change in creatinine.

We analyzed patient data according to the treatment group to which patients had been assigned, according to the intention-to-treat principle. Data are presented as mean \pm standard deviation, median (and interquartile range [IQR]) or number (and percentage), as appropriate. Results are expressed as the remote ischemic preconditioning group relative to the sham group. The CK-MB data were analyzed as multiples of the upper limit of normal, to account for between-centre differences in assays. Differ-

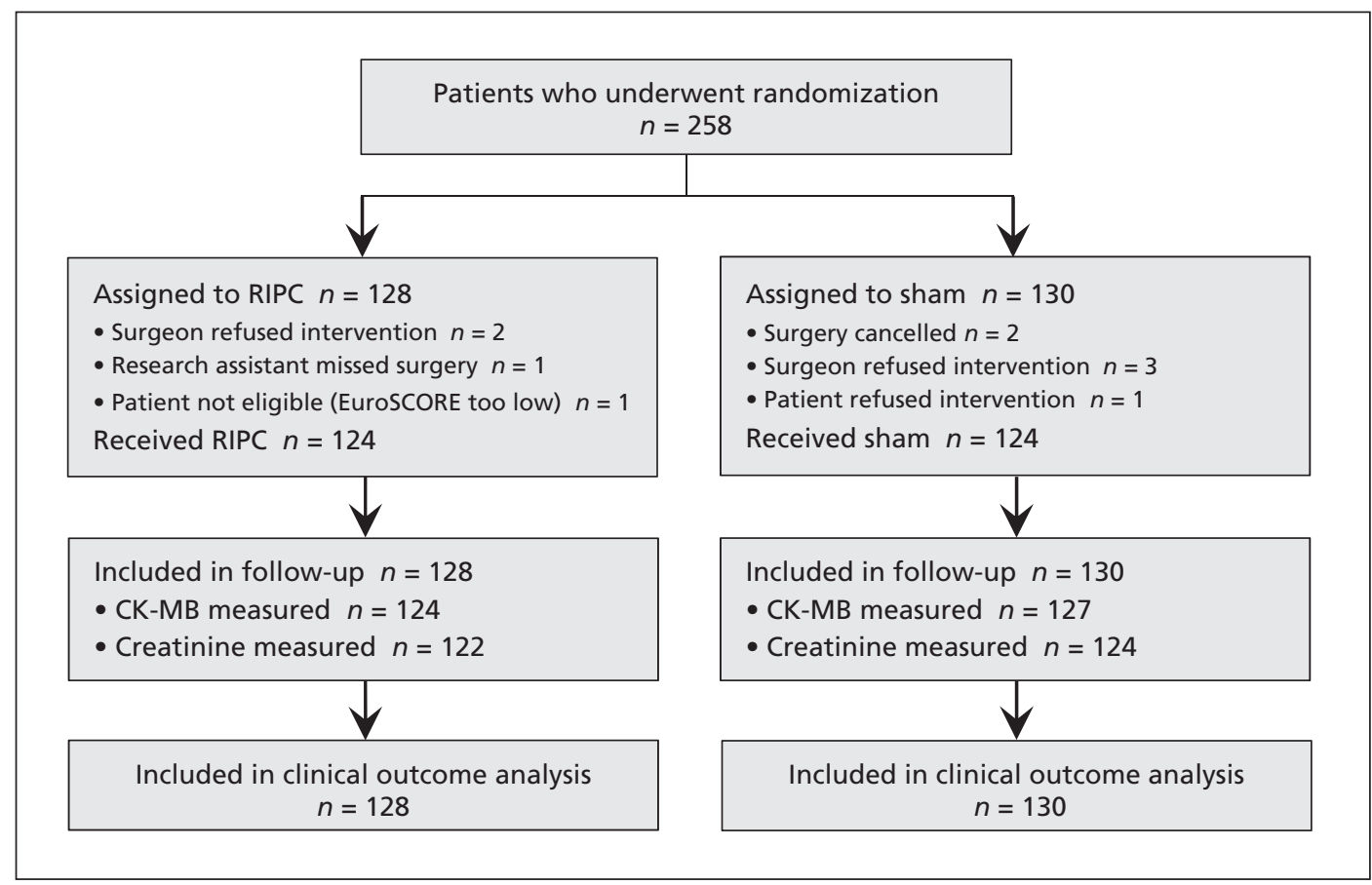

Figure 1: Flow chart for patients in the Remote IMPACT study of remote ischemic preconditioning (RIPC). CK-MB = creatine kinase-myocardial band, EuroSCORE = European System for Cardiac Operative Risk Evaluation. 
ences between groups were calculated by comparing the log-transformed concentrations, to account for the right-skewed distribution. Patients with no postoperative measurement of CK-MB were excluded from the primary analysis of this variable but were included in a sensitivity analysis using multiple imputation of peak concentration. ${ }^{23}$ Change in serum creatinine was computed by analysis of covariance, with preoperative creatinine level and treatment group as covariates and the highest recorded serum creati-

\begin{tabular}{|c|c|c|}
\hline \multirow[b]{2}{*}{ Characteristic } & \multicolumn{2}{|c|}{ Group; no. (\%) of patients* } \\
\hline & $\begin{array}{c}\text { RIPC } \\
n=128\end{array}$ & $\begin{array}{l}\text { Sham } \\
n=130\end{array}$ \\
\hline Age, yr, mean \pm SD & $72.1 \pm 12.0$ & $72.3 \pm 13.0$ \\
\hline Sex, male & $72(56.3)$ & $79(60.8)$ \\
\hline EuroSCORE, median (IQR) & $7.5(6.0$ to 9.0$)$ & 7.0 (6.0 to 9.0$)$ \\
\hline \multicolumn{3}{|l|}{ Comorbidity } \\
\hline Congestive heart failure & $45(35.2)$ & $30(23.1)$ \\
\hline Previous MI & $41(32.0)$ & $35(26.9)$ \\
\hline Atrial fibrillation & $36(28.1)$ & $29(22.3)$ \\
\hline Previous cardiac surgery & $29(22.7)$ & $21(16.2)$ \\
\hline Stroke & $10 \quad(7.8)$ & $12 \quad(9.2)$ \\
\hline Peripheral vascular disease & $17(13.3)$ & $15(11.5)$ \\
\hline Diabetes mellitus & $39(30.5)$ & $40(30.8)$ \\
\hline Dialysis dependent & $5 \quad(3.9)$ & $5 \quad(3.8)$ \\
\hline Treated with a sulfonylurea & $8 \quad(6.3)$ & $18(13.8)$ \\
\hline $\begin{array}{l}\text { Preoperative creatinine, } \mu \mathrm{mol} / \mathrm{L} \text {, } \\
\text { median (IQR) } \dagger\end{array}$ & 97 (76 to 113$)$ & 93 (74 to 119$)$ \\
\hline \multicolumn{3}{|l|}{ Procedure } \\
\hline Isolated CABG & $26(20.3)$ & $38(29.2)$ \\
\hline Isolated valve surgery & $35(27.3)$ & $33(25.4)$ \\
\hline$C A B G+$ valve surgery or other & $45(35.2)$ & $38(29.2)$ \\
\hline Other & $22(17.2)$ & $21(16.2)$ \\
\hline Bypass time, min, mean $\pm S D$ & $142.6 \pm 86.9$ & $132.7 \pm 63.7$ \\
\hline Off-pump procedure & $2 \quad(1.6)$ & $5 \quad(3.8)$ \\
\hline Cross-clamp time, min, mean \pm SD & $100.3 \pm 48.0$ & $97.9 \pm 51.2$ \\
\hline No. of grafts, median (IQR) $\ddagger$ & $2.0(1.0$ to 3.0$)$ & 3.0 (2.0 to 3.0$)$ \\
\hline Hypothermic arrest & $11 \quad(8.6)$ & $9 \quad(6.9)$ \\
\hline Anesthetic used & & $n=128$ \\
\hline Volatile gas & $107(83.6)$ & $109(85.2)$ \\
\hline Propofol & $95(74.2)$ & $100(78.1)$ \\
\hline \multicolumn{3}{|c|}{$\begin{array}{l}\text { Note: } \mathrm{CABG}=\text { coronary artery bypass graft, EuroSCORE }=\text { European System for Cardiac } \\
\text { Operative Risk Evaluation, IQR = interquartile range, } \mathrm{MI}=\text { myocardial infarction, RIPC = } \\
\text { remote ischemic preconditioning, SD = standard deviation. } \\
\text { *Except where indicated otherwise. } \\
\text { +Excluding patients who underwent preoperative dialysis. Sample sizes were } 122 \text { in the RIPC } \\
\text { group and } 124 \text { in the sham group. } \\
\text { fFor patients who underwent CABG (isolated or combined with another procedure). }\end{array}$} \\
\hline
\end{tabular}

nine within 4 days after surgery as the outcome. A sensitivity analysis using multiple imputation of missing serum creatinine values was also performed, as were analyses adjusting for history of heart failure and isolated CABG procedures compared with all other procedures, using linear or logistic regression as appropriate..$^{23}$

\section{Results}

In total, 128 patients were assigned to undergo remote ischemic preconditioning and 130 patients were assigned to the sham group (Figure 1). No patients were lost to follow-up. The 2 groups were similar at randomization and had similar operative characteristics (Table 1), although there were more patients with a history of congestive heart failure, previous cardiac surgery and previous MI in the remote ischemic preconditioning group, and fewer patients in this group underwent an isolated CABG procedure. Of the 258 patients at randomization, 124 (96.9\%) in the preconditioning group and 124 (95.4\%) in the sham group received the intended treatment as assigned (Figure 1).

Postoperative data for CK-MB were available for 251 patients (124 in the preconditioning group and 127 in the sham group). The median peak level was 3.5 (IQR 2.3 to 6.7) times the upper limit of normal for the preconditioning group and 3.3 (IQR 2.0 to 5.6) times the upper limit of normal in the sham group (Figure 2). The mean difference in log-transformed values was not statistically significant (absolute mean difference $0.15,95 \%$ confidence interval $[\mathrm{CI}]$ -0.07 to 0.36 ). Sensitivity analyses using multiple imputations to account for the 7 patients with missing data for this variable did not alter the results (absolute mean difference in logtransformed values $0.14,95 \% \mathrm{CI}-0.06$ to 0.35 ). Similarly, sensitivity analyses adjusting for a history of heart failure and type of surgery did not materially change the results (absolute mean difference $0.13,95 \% \mathrm{CI}-0.09$ to 0.34 ).

Of the 248 patients who did not require dialysis at baseline, data for change in creatinine level were available for 246 (122 in the preconditioning group and 124 in the sham group). The median peak postoperative change in creatinine was $16.9 \mu \mathrm{mol} / \mathrm{L}$ in the preconditioning group and $14.6 \mu \mathrm{mol} / \mathrm{L}$ in the sham group (Figure 3). The mean difference in log-transformed concentrations was not statistically significant (absolute mean difference $0.06,95 \% \mathrm{CI}-0.10$ to 0.23 ). Sensitivity analyses using multiple imputations to account for the 2 patients with missing creatinine data did not alter the results (absolute mean difference $0.06,95 \%$ CI -0.09 to 0.22 ). Similarly, sensitivity analyses adjusting for a history 
of heart failure and type of surgery did not materially change the results (absolute mean difference $0.05,95 \% \mathrm{CI}-0.11$ to 0.22 ).

The 2 groups did not differ significantly with respect to median length of stay in the intensive care unit (49.6 [IQR 25.2 to 91.4] h for the preconditioning group and 40.7 [IQR 23.9 to 73.4] $\mathrm{h}$ for the sham group; $p=0.08$ ) or median length of stay in the hospital (10.0 [IQR 7.0 to $16.5] \mathrm{d}$ for the preconditioning group and 9.0 [IQR 7.0 to 14.0) $\mathrm{d}$ for the sham group; $p=0.5$ ). The number of patients with prolonged use of vasopressors ( $>4 \mathrm{~h}$ during stay in the intensive care unit) was not significantly different (73/128 [57.0\%] in the preconditioning group and 68/128 [53.1\%] in the sham group; $p=0.4$ ). The groups did not differ significantly with respect to risk of MI, acute kidney injury, stroke or all-cause mortality within 6 months after randomization (Table 2). Deaths were of similar cause for the 2 groups (cardiovascular cause for 12 of 13 deaths in the preconditioning group and 8 of 9 deaths in the sham group), and timing of deaths relative to surgery was also similar (Appendix 1, available at www.cmaj.ca/lookup/ suppl/doi:10.1503/cmaj.150632/-/DC1).

At 6 months after randomization, serious adverse events had occurred in 33 patients $(25.8 \%)$ in the preconditioning group and 30 patients $(23.1 \%)$ in the sham group $(p=0.6)$. Venous thrombosis occurred in 1 patient in the sham group and no patients in the preconditioning group, and no nerve compression injuries were identified.

\section{Interpretation}

In our blinded international trial involving 258 patients at high risk of postoperative MI and acute kidney injury, remote ischemic preconditioning did not reduce peak CK-MB in the first 24 hours or creatinine in the first 4 days after surgery. Although remote ischemic preconditioning appears safe, it yielded no demonstrable benefit in this trial. Given the lack of an effect on these surrogate outcomes, if remote ischemic preconditioning has any patient-important effect on patients undergoing cardiac surgery, it is likely very small.

The effect of remote ischemic preconditioning on cardiac enzymes and kidney function has varied among studies. Some differences may be due to differences in the preconditioning regimen. However, recent meta-analyses have showed reductions in cardiac enzymes irrespective of the preconditioning regimen..$^{24,25}$ Furthermore, our regimen was previously shown to have a biological effect. ${ }^{26}$

Some patient populations may not derive a benefit. Patients with chronic intermittent ischemia may be naturally preconditioned (e.g., one-third of our patients had a history of prior coronary artery disease, compared with $15 \%$ in the largest trial suggesting benefit ${ }^{9}$ ). Alternatively, the patients in our study were at high risk and undergoing more complicated surgery and may have been subject to intraoperative ischemia-reperfusion injuries exceeding the protective capacity of remote ischemic preconditioning. Finally, other medications or conditions used frequently in cardiac surgery may mitigate the effects of preconditioning. ${ }^{27}$ If so, however, the added value of remote ischemic preconditioning in cardiac surgery is highly questionable.

Remote ischemic preconditioning may not be effective, and the results from prior trials may simply represent false-positive findings. Indeed, meta-analyses of this procedure in cardiac surgery have suggested that the reduction in release of cardiac enzymes was small, with standardized mean differences ranging from -0.28 to $-0.3{ }^{24,25}$ Recent trials have suggested reduced mortality and reduced rates of acute kidney injury, ${ }^{28,29}$ but these results are based on few events, and the estimated effects are likely to be unstable. ${ }^{30}$ Recent larger trials and the cumulative evidence in meta-analyses updated for recent trials,

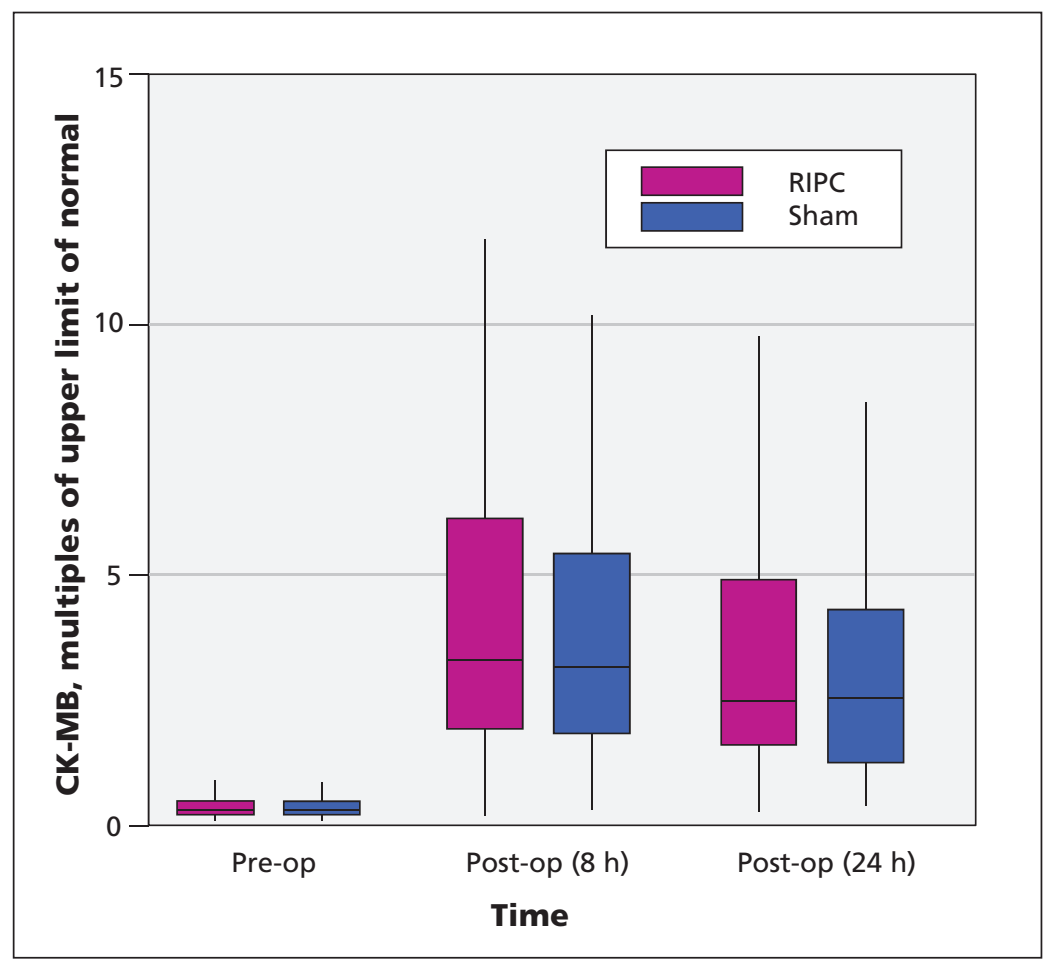

Figure 2: Serum creatine kinase-myocardial band (CK-MB), as multiples of the upper limit of normal, for patients in the remote ischemic preconditioning (RIPC) and sham therapy groups. For each data point, the central horizontal bar represents the median, the box shows the interquartile range (25th to 75th percentile), and the lower and upper whiskers represent the 2.5th and 97.5th percentiles, respectively. 
including our own, do not support benefits in terms of death or MI (Appendices 2 and 3, available at www.cmaj.ca/lookup/suppl/doi:10.1503/ cmaj.150632/-/DC1). ${ }^{24,31-33}$

The effects of remote ischemic preconditioning on acute kidney injury are uncertain (Appen- dix 4, available at www.cmaj.ca/lookup/suppl/ doi:10.1503/cmaj.150632/-/DC1). ${ }^{34}$ However, amelioration of acute kidney injury, indicated by a small rise in serum creatinine, has not led to improvements in patient-important outcomes with other interventions in cardiac surgery. ${ }^{35}$

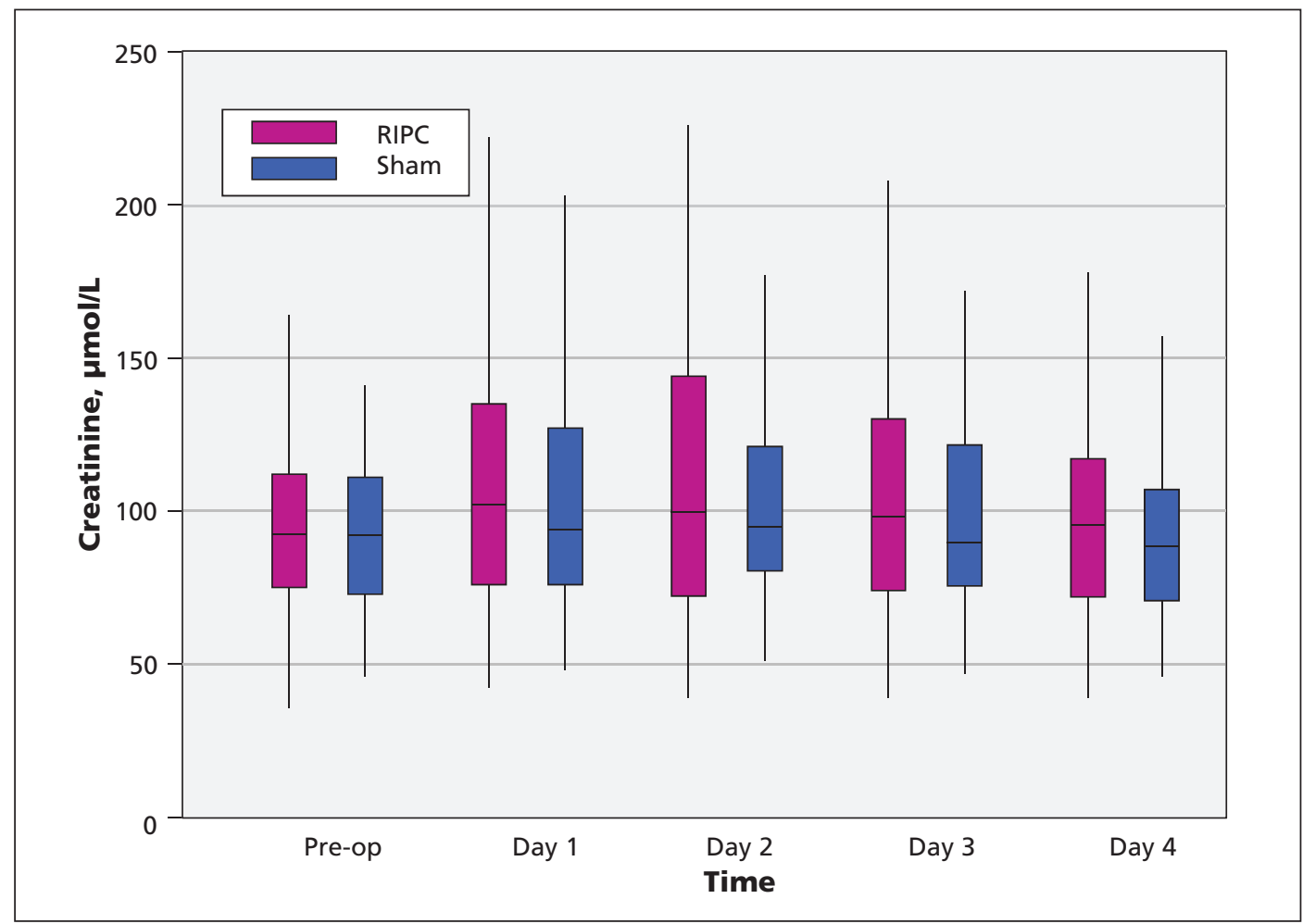

Figure 3: Serum creatinine levels in the remote ischemic preconditioning (RIPC) and sham therapy groups. For each data point, the central horizontal bar represents the median, the box shows the interquartile range (25th to 75th percentile), and the lower and upper whiskers represent the 2.5 th and 97.5 th percentiles, respectively.

Table 2: Selected secondary clinical outcomes up to 6 months after randomization in the Remote IMPACT study

\begin{tabular}{|c|c|c|c|}
\hline \multirow[b]{2}{*}{ Outcome } & \multicolumn{2}{|c|}{ Group; no. $(\%)$ of patients } & \multirow[b]{2}{*}{$\operatorname{RR}(95 \% \mathrm{Cl})$} \\
\hline & $\begin{array}{c}\text { RIPC } \\
n=128\end{array}$ & $\begin{array}{c}\text { Sham } \\
n=130\end{array}$ & \\
\hline Myocardial infarction & $32(25.0)$ & $24(18.5)$ & 1.35 (0.85 to 2.17$)$ \\
\hline \multicolumn{4}{|l|}{ Acute kidney injury* } \\
\hline Any & $27(22.1)$ & $25(20.2)$ & 1.10 (0.68 to 1.78$)$ \\
\hline Mild & $11(9.0)$ & $15(12.1)$ & \\
\hline Moderate & $8 \quad(6.6)$ & $8(6.5)$ & \\
\hline Severe, including acute dialysis & $8 \quad(6.6)$ & $2(1.6)$ & \\
\hline Acute dialysis & $6 \quad(4.9)$ & $1(0.8)$ & \\
\hline Stroke & $6 \quad(4.7)$ & $6(4.6)$ & 1.02 (0.34 to 3.07$)$ \\
\hline Death & $13(10.2)$ & $9 \quad(6.9)$ & $1.47(0.65$ to 3.31$)$ \\
\hline \multicolumn{4}{|c|}{$\begin{array}{l}\text { Note: } \mathrm{Cl}=\text { confidence interval, } \mathrm{RIPC}=\text { remote ischemic preconditioning, } \mathrm{RR}=\text { relative risk. } \\
\text { *Excluding patients who underwent preoperative dialysis. Sample sizes for this outcome were } 122 \text { patients in the RIPC group } \\
\text { and } 124 \text { patients in the sham group. Mild = increase in serum creatinine of } 150 \% \text { to } 200 \% \text { or increase of at least } 26.4 \mu \mathrm{mol} / \mathrm{L} ; \\
\text { moderate }=\text { increase in serum creatinine of greater than } 200 \% \text { up to } 300 \% \text {; severe }=\text { increase in serum creatinine greater than } \\
300 \% \text { or increase to level greater than } 354 \mu \mathrm{mol} / \mathrm{L}, \text { with an acute increase of at least } 44 \mu \mathrm{mol} / \mathrm{L} \text {, or need for acute dialysis. }{ }^{22} \\
\text { These are mutually exclusive categories, and the most severe category that a patient fulfilled was used. }\end{array}$} \\
\hline
\end{tabular}


Although it is impossible to rule out an effect of preconditioning on patient-important outcomes, a substantial effect seems improbable. The clinical benefits from preconditioning in cardiac surgery would be reliably apparent only if very large trials were conducted. Such trials are estimated to require more than 7500 high-risk participants, whereas the total number of participants in trials of this therapy to date is about 5500 , with only a minority having high risk. ${ }^{36}$

\section{Limitations}

These results must be considered in light of the study's limitations. Our trial was not large and may have been underpowered to reliably detect a difference in CK-MB or creatinine level. Indeed, we expected a greater change in creatinine (by a factor of almost 2). Although the observed change in and distribution of creatinine were smaller than anticipated, the change in and distribution of CK-MB were as predicted and provided adequate power to detect a modest treatment effect. It is also possible that imbalances in baseline risk due to chance confounded our results. For example, there were more isolated CABG procedures and fewer patients with a history of heart failure in the sham group, which may have resulted in lower mean changes in CK-MB and creatinine relative to the preconditioning group. An imbalance in baseline risk would need to be large to mask a large benefit, and such a large imbalance in risk is not supported by our adjusted sensitivity analyses or the observed balance in the EuroSCORE, an overall marker of prognosis. ${ }^{37}$

\section{Conclusion}

These results suggest that remote ischemic preconditioning is unlikely to have an important effect on myocardial or kidney injury in patients at high risk of complications after cardiac surgery. Although it is possible that preconditioning improves patientimportant outcomes, current data do not support its use in cardiac surgery, and small trials suggesting an effect should be regarded with caution.

\section{References}

1. Ramsay J, Shernan S, Fitch J, et al. Increased creatine kinase MB level predicts postoperative mortality after cardiac surgery independent of new Q waves. J Thorac Cardiovasc Surg 2005;129: 300-6.

2. Shernan SK, Fitch JC, Nussmeier NA, et al. Impact of pexelizumab, an anti-C5 complement antibody, on total mortality and adverse cardiovascular outcomes in cardiac surgical patients undergoing cardiopulmonary bypass. Ann Thorac Surg 2004;77:942-9.

3. Karkouti K, Wijeysundera DN, Yau TM, et al. Acute kidney injury after cardiac surgery: focus on modifiable risk factors. Circulation 2009; 119:495-502.

4. Rady MY, Ryan T, Starr NJ. Perioperative determinants of morbidity and mortality in elderly patients undergoing cardiac surgery. Crit Care Med 1998;26:225-35.

5. Weman SM, Karhunen PJ, Penttila A, et al. Reperfusion injury associated with one-fourth of deaths after coronary artery bypass grafting. Ann Thorac Surg 2000;70:807-12.

6. Shernan SK. Perioperative myocardial ischemia reperfusion injury. Anesthesiol Clin North America 2003;21:465-85.

7. Walsh SR, Tang T, Sadat U, et al. Cardioprotection by remote ischaemic preconditioning. Br J Anaesth 2007;99:611-6.

8. Shimizu M, Tropak M, Diaz RJ, et al. Transient limb ischemia remotely preconditions through a humoral mechanism acting directly on the myocardium: evidence suggesting cross-species protection. Clin Sci (Lond) 2009;117:191-200.

9. Thielmann M, Kottenberg E, Kleinbongard P, et al. Cardioprotective and prognostic effects of remote ischaemic preconditioning in patients undergoing coronary artery bypass surgery: a single-centre randomised, double-blind, controlled trial. Lancet 2013;382:597-604.

10. Jones BO, Pepe S, Sheeran FL, et al. Remote ischemic preconditioning in cyanosed neonates undergoing cardiopulmonary bypass: a randomized controlled trial. J Thorac Cardiovasc Surg 2013;146:1334-40.

11. Zimmerman RF, Ezeanuna PU, Kane JC, et al. Ischemic preconditioning at a remote site prevents acute kidney injury in patients following cardiac surgery. Kidney Int 2011;80:861-7.

12. Choi YS, Shim JK, Kim JC, et al. Effect of remote ischemic preconditioning on renal dysfunction after complex valvular heart surgery: a randomized controlled trial. J Thorac Cardiovasc Surg 2011;142:148-54.

13. Thielmann M, Kottenberg E, Boengler K, et al. Remote ischemic preconditioning reduces myocardial injury after coronary artery bypass surgery with crystalloid cardioplegic arrest. Basic Res Cardiol 2010;105:657-64.

14. Zhou W, Zeng D, Chen R, et al. Limb ischemic preconditioning reduces heart and lung injury after an open heart operation in infants. Pediatr Cardiol 2010;31:22-9.

15. Ali ZA, Callaghan CJ, Lim E, et al. Remote ischemic preconditioning reduces myocardial and renal injury after elective abdominal aortic aneurysm repair: a randomized controlled trial. Circulation 2007;116(11 Suppl):I98-105.

16. Cheung MM, Kharbanda RK, Konstantinov IE, et al. Randomized controlled trial of the effects of remote ischemic preconditioning on children undergoing cardiac surgery: first clinical application in humans. J Am Coll Cardiol 2006;47:2277-82.

17. Hausenloy DJ, Mwamure PK, Venugopal V, et al. Effect of remote ischaemic preconditioning on myocardial injury in patients undergoing coronary artery bypass graft surgery: a randomised controlled trial. Lancet 2007;370:575-9.

18. Nashef SA, Roques F, Michel P, et al. European system for cardiac operative risk evaluation (EuroSCORE). Eur J Cardiothorac Surg 1999;16:9-13.

19. Malik M, Chauhan S, Malik V, et al. Is EuroSCORE applicable to Indian patients undergoing cardiac surgery? Ann Card Anaesth 2010;13:241-5

20. Wang C, Yao F, Han L, et al. Validation of the European System for Cardiac Operative Risk Evaluation (EuroSCORE) in Chinese heart valve surgery patients. J Heart Valve Dis 2010;19:21-7.

21. Domanski MJ, Mahaffey K, Hasselblad V, et al. Association of myocardial enzyme elevation and survival following coronary artery bypass graft surgery. JAMA 2011;305:585-91.

22. Mehta RL, Kellum JA, Shah SV, et al. Acute Kidney Injury Network: report of an initiative to improve outcomes in acute kidney injury. Crit Care 2007;11:R31.

23. Schafer JL. Analysis of incomplete multivariate data. New York: Chapman and Hall; 1997.

24. Brevoord D, Kranke P, Kuijpers M, et al. Remote ischemic conditioning to protect against ischemia-reperfusion injury: a systematic review and meta-analysis. PLoS One 2012;7:e42179.

25. D'Ascenzo F, Cavallero E, Moretti C, et al. Remote ischaemic preconditioning in coronary artery bypass surgery: a metaanalysis. Heart 2012;98:1267-71.

26. Loukogeorgakis SP, Williams R, Panagiotidou AT, et al. Transient limb ischemia induces remote preconditioning and remote postconditioning in humans by a K(ATP)-channel dependent mechanism. Circulation 2007;116:1386-95.

27. $\mathrm{Yu} \mathrm{CH}$, Beattie WS. The effects of volatile anesthetics on cardiac ischemic complications and mortality in CABG: a metaanalysis. Can J Anaesth 2006;53:906-18.

28. Walsh M, Srinathan SK, McAuley DF, et al. The statistical significance of randomized controlled trial results is frequently fragile: a case for a fragility index. J Clin Epidemiol 2014;67:622-8.

29. Zarbock A, Schmidt C, Van Aken H, et al. Effect of remote ischemic preconditioning on kidney injury among high-risk patients undergoing cardiac surgery: a randomized clinical trial. JAMA 2015;313:2133-41.

30. Thorlund $\mathrm{K}$, Imberger $\mathrm{G}$, Walsh $\mathrm{M}$, et al. The number of patients and events required to limit the risk of overestimation of intervention effects in meta-analysis - a simulation study. 
PLoS One 2011;6:e25491.

31. Hausenloy DJ, Candilio L, Evans R, et al. Remote ischemic preconditioning and outcomes of cardiac surgery. $N$ Engl J Med 2015;373:1408-17.

32. Meybohm P, Bein B, Brosteanu O, et al. A multicenter trial of remote ischemic preconditioning for heart surgery. $N$ Engl J Med 2015;373:1397-407.

33. Remote Preconditioning Trialists' Group, Healy DA, Khan WA, Wong CS, et al. Remote preconditioning and major clinical complications following adult cardiovascular surgery: systematic review and meta-analysis. Int J Cardiol 2014;176:20-31.

34. Yang $\mathrm{Y}$, Lang $\mathrm{XB}$, Zhang $\mathrm{P}$, et al. Remote ischemic preconditioning for prevention of acute kidney injury: a meta-analysis of randomized controlled trials. Am J Kidney Dis 2014;64:574-83.

35. Garg AX, Devereaux PJ, Yusuf S, et al. Kidney function after off-pump or on-pump coronary artery bypass graft surgery: a randomized clinical trial. JAMA 2014;311:2191-8.

36. Whitlock R, Teoh K, Vincent J, et al. Rationale and design of the steroids in cardiac surgery trial. Am Heart J 2014;167:660-5.

37. Chu R, Walter SD, Guyatt G, et al. Assessment and implication of prognostic imbalance in randomized controlled trials with a binary outcome - a simulation study. PLoS One 2012;7:e36677.

Affiliations: Population Health Research Institute (Walsh, Whitlock, Vincent, Rao-Melacini, Thabane, Devereaux), Hamilton, Ont.; McMaster University (Walsh, Whitlock, Syed, VanHelder, Guyatt, Rao-Melacini, Thabane, Devereaux), Hamilton, Ont.; London Health Sciences Centre (Garg, Lavi), Western University, London, Ont.; Dalhousie University (Légaré), Halifax, NS; Cleveland Clinic (Duncan, Nasr, Sessler), Cleveland, Ohio; Maine Medical Center (Zimmerman, Kramer), Portland, Me.; Wake Forest University (Miller, Gardner), Winston-Salem, NC; Sunnybrook Health Sciences Centre (Fremes), University of Toronto, Toronto, Ont.; University of Calgary (Kieser, Ali), Calgary, Alta; All India Institute of Medical Sciences (Karthikeyan), New Delhi, India; The Chinese University of Hong Kong (Chan, Ho), Hong Kong SAR, China

Funding: This study was funded by peer-reviewed grants from the Hamilton Health Sciences New Investigators Fund
(NIF-09223) and the Canadian Network and Centre for Trials Internationally. The Population Health Research Institute (Hamilton, Ont.) coordinated the study, managed the data and undertook analyses under the supervision of the principal investigators. The funders had no role in the design or conduct of the trial; recruitment of patients; collection, analysis or interpretation of the data; writing of the manuscript; the decision to submit it for publication; or any other aspect of the trial. The corresponding author had full access to all trial data.

Michael Walsh was supported by a New Investigator Award from the Kidney Research Scientist Core Education and National Training Program. Amit Garg was supported by a Clinician Scientist Award from the Canadian Institutes of Health Research. Andra Duncan was supported by a Mentored Patient-Oriented Research Career Development Award from the National Heart, Lung, and Blood Institute (HL093065). Ganesan Karthikeyan was supported by a Canadian Institutes of Health Research Hope Scholarship. P.J. Devereaux was supported by a Career Scientist Award from the Heart and Stroke Foundation.

Contributors: All of the authors contributed to the study design, the collection and interpretation of the data, and the critical revision of the manuscript. Michael Walsh, Amit Garg, Purnima Rao-Melacini and P.J. Devereaux contributed to the data analysis. Michael Walsh and P.J. Devereaux wrote the first draft of the manuscript. All of the authors approved the final version to be published and agreed to act as guarantors of the work.

Acknowledgements: The authors acknowledge the efforts of Prof. Malcolm J. Underwood (Chinese University of Hong Kong) and Dr. Gaurav Purohit (All India Institute of Medical Sciences) in facilitating the logistics of conducting this study in the Hong Kong and Indian centres, respectively.

Data sharing: The full protocol and all study data are held at the Population Health Research Institute, Hamilton, Ont. Access to data may be granted upon request.

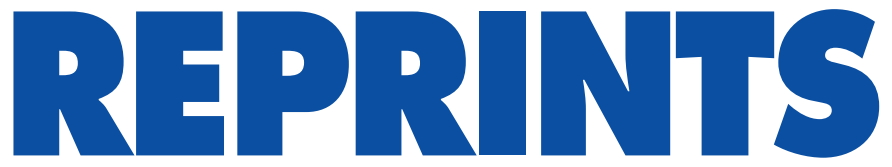

\section{We have partnered with Sheridan Press!}

To purchase commercial article reprints and
e-prints or to request a quote, please contact

Matt Neiderer

Content Sales

Sheridan Content Services
$800635-7181 \times 8265$

matt.neiderer@sheridan.com

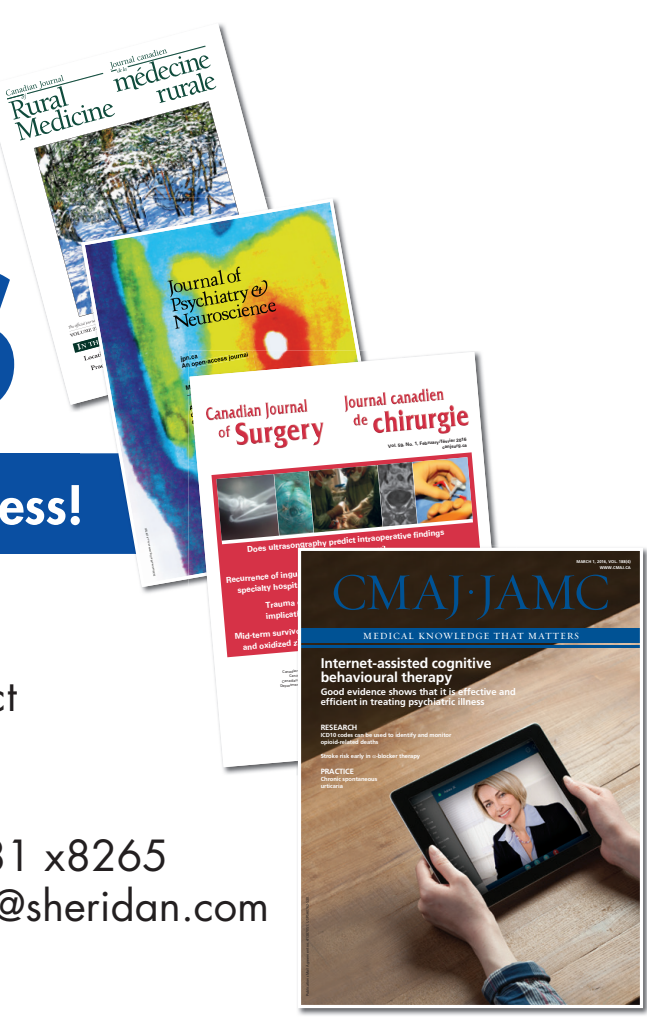

